\title{
A Density Functional Theory Study on the Interaction of Paraffins, Olefins and Acetylenes with Na-ETS-10
}

\author{
Renjith S. Pillai, ${ }^{1}$ Miguel Jorge, ${ }^{2}{ }^{J}$ osé R. B. Gomes ${ }^{1, *}$
}

${ }^{1}$ CICECO, Departamento de Química, Universidade de Aveiro, Campus Universitário de Santiago, P-3810-193 Aveiro, Portugal

${ }^{2}$ Department of Chemical and Process Engineering, University of Strathclyde, 75 Montrose Street, Glasgow G1 1XJ, United Kingdom

*Corresponding author. E-mail: jrgomes@ua.pt Phone: +351234401423

Fax: +351 234401470 


\begin{abstract}
High demand for economically viable separation processes like adsorptive separation for mixtures of hydrocarbons drives the need for understanding the interaction of hydrocarbons with titanosilicate adsorbents, to replace the energy intensive cryogenic hydrocarbon separation. Density functional theory (DFT) was used to optimize the geometries and calculate the enthalpies for the interactions between paraffins $\left(\mathrm{C}_{2} \mathrm{H}_{6}, \mathrm{C}_{3} \mathrm{H}_{8}\right)$, olefins $\left(\mathrm{C}_{2} \mathrm{H}_{4}, \mathrm{C}_{3} \mathrm{H}_{6}\right)$ and acetylenes $\left(\mathrm{C}_{2} \mathrm{H}_{2}, \mathrm{C}_{3} \mathrm{H}_{4}\right)$ with a cluster model of the Engelhard titanosilicatehaving sodium extra framework cations (Na-ETS-10). The DFT calculations were performed with theM06-L exchange correlation functional and were corrected for the basis set superposition error with the counterpoise method. The calculated enthalpies for the interaction of hydrocarbons with $\mathrm{Na}-$ ETS-10 decrease with the decrease in the number of carbon atoms, in the order acetylenes >olefins >paraffins, and compare well with experimental data available in the literature. The enthalpies calculated at the M06-L/6-31++G** level of theory for the two extreme cases, i.e., strongest and weakest interactions, are $-62.8 \mathrm{~kJ} \cdot \mathrm{mol}^{-1}\left(\mathrm{C}_{3} \mathrm{H}_{4}\right)$ and $-26.9 \mathrm{~kJ} \cdot \mathrm{mol}^{-1}\left(\mathrm{C}_{2} \mathrm{H}_{6}\right)$. Additionally, the calculated vibrational frequencies are in good agreement with the characteristic vibrational modes of ETS-10 and of the interactions of hydrocarbons with $\mathrm{Na}^{+}$in the 12membered channel in ETS-10.
\end{abstract}

Keywords: ETS-10; Sorption;Separation;Hydrocarbons; DFT calculations 


\section{Introduction}

The separation of mixtures of hydrocarbons is a commercially important process in the (petro)chemical industries[1]. Unsaturated hydrocarbons, ethene (ethylene) and propene (propylene), are the most important and largest commercial volume petrochemicals in the world today. For example, ethene is used as starting material for the manufacture of various chemical products such as polyethylene, ethene-propene rubber, vinyl chloride, ethene chloride, and acetaldehyde; saturated hydrocarbons find wide application as fuels[1-3]; and acetylenes are the main feed stock for the welding industry. Furthermore, olefins are selectively oxidized to the corresponding oxide, e.g. ethene oxide, and these oxides are used as raw materials for the synthesis of various chemical products[4, 5]. Ethene, propene and ethyne are recovered from a mixture of cracked gases obtained after naphtha or gas cracking. Current technology being used for recovery of olefins employs primarily cryogenic distillation, which utilizes the difference in boiling points of the constituent gases[3,6]. Since it is known to be an expensive and energy intensive technique, researchers have been focusing on alternative technologies such as adsorption, chemical absorption and membranes for separation of olefins from paraffins. Of the various alternative technologies, adsorption appears to be quite promising. However, the key to development of an economically viable adsorption separation process lies in development of an adsorbent that offers an ideal adsorption capacity and selectivity for olefin/paraffin at a given temperature and pressure range[7-12].The adsorption capacities and selectivity for hydrocarbonscan then be exploited, for instance, to design temperature/pressure swing adsorption (TSA/PSA) processes for the petrochemical industry.

As a new class of nanoporous materials, titanosilicates have been used in various separation processes with remarkable separation properties. An interesting material belonging to 
this family is the Engelhard titanosilicate ETS-10[13, 14]. ETS-10 emerged as an attractive adsorbent for gas separation since its introduction by Kuznicki et al [13]. Because of the three dimensional porous network combined with the mobility of extra-framework cations in their pores, ETS-10arises as a potential adsorbent for olefin/paraffin separation[15-17]. In fact, AlBaghli et al. [15] and Anson et al. [16]suggested ETS-10 as an adsorbent for hydrocarbon separation processes. Furthermore, Al-Baghli et al.[18]reported adsorption isotherms and isosteric heats of adsorption for methane, ethane and ethene in ETS-10, Anson et al. [19] used ETS-10 for ethene separation from ethane by an adsorptive separation technique, while Avila et al. [20] evidenced the better capability of ETS-10 to separate ethane from a methane/ethane mixture.

To design a proper PSA/TSA technique to separate olefins from paraffins using ETS-10, it is necessary to determine accurate enthalpies of adsorption. Very recently, quantum mechanical density functional theory (DFT) calculations performed with the M06-L functional and all electron basis sets, combined with an Na-ETS-10 cluster model based on a single -O-TiO- chain model with two (2Ti) titanium atoms incorporated in half portion of a 12-membered ring (MR), Figure 1,were shown to provide enthalpies of interaction for methane, nitrogen and carbon dioxide in very good agreement with available experimental isosteric heats [21]. Enthalpic differences between calculated and experimental data were below $\sim 1 \mathrm{kcal} \cdot \mathrm{mol}^{-}$ ${ }^{1}$.Additionally, vibrational frequencies for the latter molecules and also for hydrogen and water interacting with the Na-ETS-10 cluster were found to compare well with vibrations determined experimentally (error within $30 \mathrm{~cm}^{-1}$ ). In agreement with earlier work published in the literature, our previous calculations [21] showed that polar $\left(\mathrm{H}_{2} \mathrm{O}\right)$, quadrupolar $\left(\mathrm{CO}_{2}\right.$ and $\left.\mathrm{N}_{2}\right)$, and apolar $\left(\mathrm{H}_{2}\right.$ and $\left.\mathrm{CH}_{4}\right)$ atmospheric gases preferentially interact with the sodium ion in the 12-MR 
channel.Guo et al.[22]used a cluster model of Na-ETS-10 composed by 102 atoms (21T model) to study the interaction of acetylene with Si-O-Si moieties, with $\mathrm{Na}^{+}$extra framework cations, and with an oxygen defective site in Na-ETS-10. They found that acetylene interacted preferentially with the $\mathrm{Na}^{+}$cations, being the adsorption energy $-46 \mathrm{~kJ} \cdot \mathrm{mol}^{-1}$ at the M06-L/6$31 \mathrm{G}(\mathrm{d}, \mathrm{p})$ level of theory, while the weakest complex was the H-bonded acetylene with Si-O-Si being the adsorption energy equal to $-24 \mathrm{~kJ} \cdot \mathrm{mol}^{-1}$. The adsorption energy on the oxygen defective site was $-33 \mathrm{~kJ} \cdot \mathrm{mol}^{-1}$.

Despite ETS-10 being considered a very good adsorbent for olefin/paraffin separation, the interaction of hydrocarbons with ETS-10 having extra framework cations was so far not studied in detail. The separation of olefins from paraffins using ETS-10 relies on close interactions between $\pi$-bonded or $\sigma$-bonded hydrocarbon molecules and the framework atoms, including the charge-balancing cations, and thus obtaining a more in-depth understanding of these interactions is crucial in this context. Based on recent successes on the application of electronic structure methods to study the interaction of gases with porous materials [21-27], the present study aims at providing an atomic level picture for the interaction of saturated and unsaturated hydrocarbons with sodium extra-framework cations in the ETS-10 structure. For that purpose, DFT calculations were used to study the interaction of three types of gaseous hydrocarbon molecules, namely, paraffins (ethane and propane), olefins (ethene and propene), and acetylenes (ethyne and propyne) with a finite cluster model of ETS-10 having extraframework sodium ions (Na-ETS-10). Energetic and structural data corresponding to the interactions of $\mathrm{C}_{2} \mathrm{H}_{6}, \mathrm{C}_{2} \mathrm{H}_{4}, \mathrm{C}_{2} \mathrm{H}_{2}, \mathrm{C}_{3} \mathrm{H}_{8}, \mathrm{C}_{3} \mathrm{H}_{6}$, and $\mathrm{C}_{3} \mathrm{H}_{4}$ in ETS-10 will be very important for the understanding of ETS-10 materials, a crucial prerequisite for their use as adsorbents. 
(a)

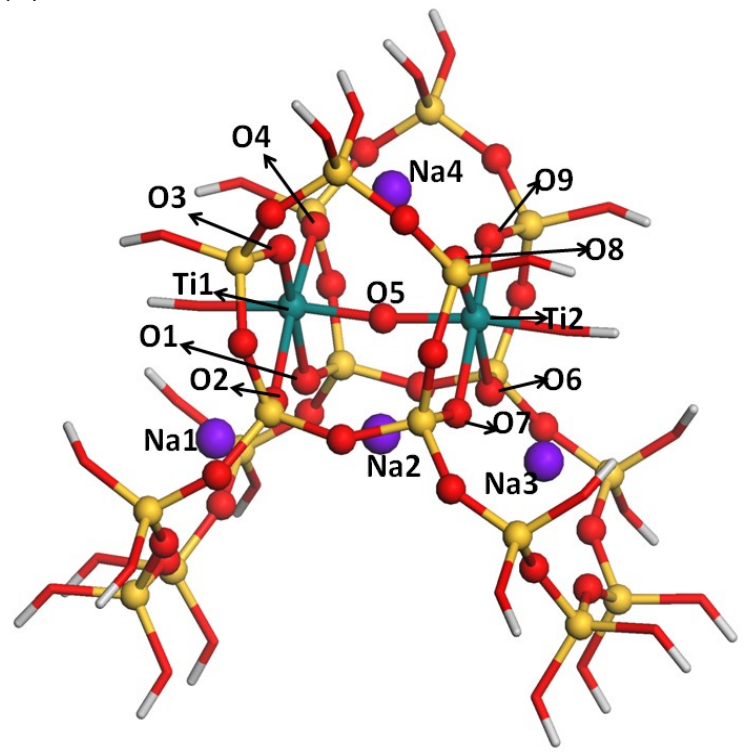

(b)

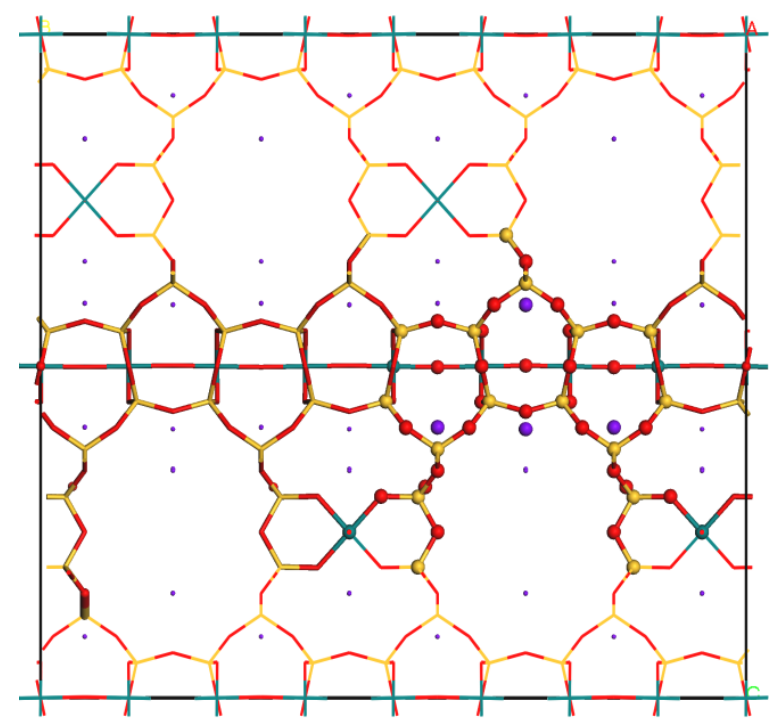

Fig. 1 View of the cluster model (a) cut from the periodic structure of NaETS-10 (polymorph B from ref. [14]) shown in (b).The spheres in (a) represent atoms fully optimized while sticks represent frozen atoms at their periodic positions. Note that terminal Si atoms were replaced by $\mathrm{H}$ in (a). Color code is: Bluish-green for Ti, yellow for $\mathrm{Si}$, red for $\mathrm{O}$, violet for $\mathrm{Na}$ and white for H.

\section{Computational details}

The density functional calculations were performed with the M06-L exchange-correlation functional [28] as implemented in the Gaussian 09 code [29]. The atomic electronic densities were described with the 6-31G basis set, augmented with polarization functions, $6-31 \mathrm{G}(\mathrm{d}, \mathrm{p})$, or with polarization and diffuse functions, $6-31++\mathrm{G}(\mathrm{d}, \mathrm{p})$, in all the atoms. Notice that diffuse functions were only considered for the atoms in the hydrocarbon molecule and in the central region of the Na-ETS-10 cluster model, i.e., in the central $\mathrm{Na}$ cation (Na2), and in the framework oxygen atoms neighboring the $\mathrm{Na} 2$ cation (atoms labeled $\mathrm{O} 1, \mathrm{O} 2, \mathrm{O}$, O6, $\mathrm{O} 7$ and $\mathrm{Na} 2$ in Figure 1a).The M06-L functional is used in this work since in a recent comparative study on the performance of nine different DFT functionals to calculate the interaction enthalpy of methane 
with a cluster model of Na-ETS-10, the M06-L approach was found to provide the best results [21].Besides,the M06-L approach together with a cluster model was found to provide very accurate energetic, vibrational and structural information for some other difficult systems such as i) adsorption of $\mathrm{CO}$ on $\mathrm{MgO}(001)[30]$, ii) the adsorption of $\mathrm{CO}$ and $\mathrm{NO}$ on Ni-doped $\mathrm{MgO}(001)$ [31], and iii) the interaction of water with open metal sites of CuBTC[32]. Very encouragingly, recent works concerning the interaction of $\mathrm{CO}$ with the (111) surfaces of $\mathrm{Rh}, \mathrm{Pt}, \mathrm{Cu}, \mathrm{Ag}$ and $\operatorname{Pd}[33]$ or the interaction of benzene, pyridine, thymine and cytosine with $\mathrm{Au}(111)$ [34]showed that the M06-L method is suitable for treating dispersion dominated interactionsof adsorbateswith metallic surfaces[35].The M06-L approach was also effectively employed to predict reaction energies in organometallic systems [36-38] and the benchmark study on the interaction of hydrocarbons and smaller gases with several zeolite clusters byZhao and Truhlar[39]shows that the M06 family of functionals is well suited to study this kind of systems.Additionally, in our very recent work on the interaction of five atmospheric gases with Na-ETS-10[21], calculated enthalpic data for methane, nitrogen and, at some extent, carbon dioxide, and calculated vibrational data for methane, nitrogen, hydrogen, carbon dioxide and water were found to be in very satisfactory agreement with experimental isosteric heats[40, 41] and infrared results[42-45], respectively. The same 2Ti cluster model used in Ref. [21] to study the interaction of $\mathrm{H}_{2} \mathrm{O}, \mathrm{CO}_{2}, \mathrm{~N}_{2}, \mathrm{H}_{2}$ and $\mathrm{CH}_{4}$ atmospheric gases was considered in this work (Figure 1a).The ETS-10 cluster model contains two Ti atoms within the -O-Ti-O-Ti-O- chain and a half portion of the 12-MR (12-member ring), and was cut out from the crystallographic cell of ETS-10 (Figure 1b).As it is common practice, all dangling bonds were terminated with hydrogen atoms (yielding hydroxyl groups). Each terminating $\mathrm{H}$ atom was placed at the same bond angle and dihedral angle as the corresponding $\mathrm{Si}$ or $\mathrm{Ti}$ atom in the extended crystal structure, and at a 
bond distance of $0.96 \AA$, which is a typical value for this type of materials [46]. Extra framework sodium ions were included to neutralize the system, and their initial positions (i.e., prior to the optimization procedure) were taken from the crystal data of Wang and Jacobson [47].

The cluster model has been chosen to model the interactions of the hydrocarbons with the cations as well as with the -O-Ti-O- chains in the large channels of ETS-10.For each of the hydrocarbons considered in this work, namely, ethane, propane, ethene, propene, ethyne and propyne, the energy of interaction, $\Delta E$, was calculated as $\Delta E=E_{\text {hydrocarbon-adsorbent }}-E_{\text {adsorbent }}-$ $E_{\text {hydrocarbon, }}$ where $E_{\text {adsorbent }}$ is the total energy of the isolated cluster model shown in Figure 1a, $E_{\text {hydrocarbon }}$ is the total energy in vacuum of the hydrocarbon (i.e., isolated $\mathrm{C}_{2} \mathrm{H}_{6}, \mathrm{C}_{2} \mathrm{H}_{4}, \mathrm{C}_{2} \mathrm{H}_{4}$, $\mathrm{C}_{3} \mathrm{H}_{8}, \mathrm{C}_{3} \mathrm{H}_{6}$, or $\mathrm{C}_{3} \mathrm{H}_{4}$ species) and $E_{\text {hydrocarbon-adsorbent }}$ is the total energy of the complex(i.e., single hydrocarbon molecule interacting with the cluster model). Thus, in the present notation, negative values for the energy of interaction mean favorable adsorption. The enthalpies of interaction at $T=0 \mathrm{~K}, \Delta H^{0 \mathrm{~K}}$,were calculated in a similar way but using total energies corrected with the zeropoint energy instead of total energies only. The enthalpies of interaction at $T=298.15 \mathrm{~K}$, $\Delta H^{298.15 \mathrm{~K}}$, were calculated from the total energies with the thermal corrections, i.e., as $\Delta H^{0 \mathrm{~K}}$ but including also the translational, rotational, vibrational and PV terms. The geometries, the energies and the enthalpies of interaction include the basis set superposition error (BSSE) corrections calculated with the counterpoise method [48].The calculated data was compared with experimental data when available in the literature[14, 47]. The structures of the different systems were fully optimized with the exception of the terminating hydroxyl groups in the Na-ETS-10 model, which were held fixed for a better representation of the rigid crystalline structure. In the case of the hydrocarbon-adsorbent system, the hydrocarbon molecule was initially positioned close to the Na2 cation (Figure 1a).This choice is supported by both previous experimental and 
computational work. Experimental studies suggest that preferential interaction sites in Na-ETS10 for $\mathrm{H}_{2}, \mathrm{~N}_{2}, \mathrm{CO}$ and $\mathrm{NO}$ [42] probe molecules and also for $\mathrm{CO}_{2}$ [45]adsorbatesare positions close to the sodium cations in the 12-membered rings. This is because Na cations in sites 1 and 3 , being located in a subsurface position of the 7-membered rings, are strongly shielded by negative charge localized on the oxygen atoms of the framework, and because Na cations in sites 4 are not accessible[42]. Similarly, the experimental in situ infrared spectroscopy studies of Kishima and Okubo [43]on the adsorption of methane in Na-ETS-10 also suggested that adsorption was preferential in the 12-membered rings but the exact location could not be ascribed and further work was suggested. Very recently, we have performed a computational study on the adsorption of methane in Engelhard titanosilicate frameworks Na-ETS-10 and Na-ETS-4 in which the preferential locations for methane in these materials were carefully explored [49].The Monte Carlo NVT simulations clearly showed methane packing at the locations in 12-membered rings close to the $\mathrm{Na} 2$ cations, which provide further support to the computational strategy followed in the present work.

The Natural Population and Topology Analyses were performed with the NBO v3.1 [5053] and with the Multiwfn v3.2.1[54] codes considering the wavefunctions calculated at the M06-L/6-31++G** level of theory.

\section{Results and Discussion}

An important aspect of the ETS-10 material is the location of the extra framework cations, especially those neighboring the large 12-MR channels, i.e., cations interacting with the -O-Ti-O- chain. Such ions are suggested to have a crucial role in the local geometry of the 
ETS-10 framework and, consequently, to have also a role in the strength of the sorbate-substrate interaction. According to Wang and Jacobson [47], the Na2 cation is coordinated to five oxygen atoms at 2.57-2.62 $\AA$ while $\mathrm{Na} 1, \mathrm{Na} 3$, and $\mathrm{Na} 4$ (cf. Figure 1a) are coordinated to eight oxygen atoms at distances $2.50-2.99 \AA$. The optimized distances between the $\mathrm{Na} 2$ ion and neighboring oxygen atoms are shorter that these experimental results. In fact, the $\mathrm{Na} 2$-oxygen distances calculated with the M06-L approach and the $2 \mathrm{Ti}$ model are $\sim 0.15 \AA$ shorter than the distances reported by Wang and Jacobson [47]to atoms O1, O2, O6 and O7, and $\sim 0.4 \AA$ shorterthan the distance to atom $\mathrm{O} 5$ [21]. The structural data obtained with the $2 \mathrm{Ti}$ model is similar to the results reported by Zimmerman et al. [24] using a 5Ti model and the ONIOM(DFT:MM) approach. Both models provide a range of calculated titanium-oxygen distances which is in very good agreement with the experimental one. Thus, the small but noticeable differencesfound for the $\mathrm{Na} 2$ ion result essentially from neglecting disordered space-filling species (e.g. water molecules) in the calculations. The consideration of such species is less relevant for the purposes of the present computational work since ETS-10 is activated by heating for use in adsorption or in catalysis. Thus, adsorbed molecules are certainly evacuated during material activation; in fact, substantial water loss at temperatures below those used in material activation has been reported for as-synthesized ETS-10 samples[55], which supports our computational strategy.

Previous experimental adsorption $[13,15,19]$ and vibrational $[42,43]$ studies disclosed that the Na2 cations, which are less coordinated than cations of the type Na1, Na3, and $\mathrm{Na} 4$, would be the primary sites for interaction with guest molecules in the 12-MR channels of ETS10 , with concomitant formation of sorbate-Na adducts [21] or $\pi$-complexes [22], depending on the adsorbate. The experimental isosteric heats for methane adsorption in ETS-10 reported in the literature are included in the interval from -20.8 to $-23.3 \mathrm{~kJ} \cdot \mathrm{mol}^{-1}$, and were deduced from the fit 
of Toth, unilan or virial three constants models to the adsorption data obtained with volumetric systems in temperature ranges around $T=298.15 \mathrm{~K}[18,41]$. These data were used to benchmark a computational strategy to obtain accurate enthalpic data for the interaction of methane with NaETS-10[21]. The enthalpy of interaction at $T=298.15 \mathrm{~K}$, calculated with the M06-L/6-31++G** approach and corrected for the BSSE, is $-20.8 \mathrm{~kJ} \cdot \mathrm{mol}^{-1}$. The effect of the BSSE corrections in the calculated interaction enthalpy was $\sim 10 \mathrm{~kJ} \cdot \mathrm{mol}^{-1}$. The sodium to methane distance was optimized to $2.88 \AA$, not far from the values reported by Guo et al [22] for propyne interaction with NaETS-10, i.e., $2.76 \AA$ and $2.87 \AA$ for the two $\mathrm{C}$ atoms in $\mathrm{HCCH}$.

\subsection{Adsorption of $\mathrm{C}_{2} \mathrm{H}_{\mathrm{x}}$ and $\mathrm{C}_{3} \mathrm{H}_{\mathrm{x}}$ hydrocarbons in ETS- 10}

The configurations optimized at the M06-L/6-31++G** level of theory for the $\mathrm{C}_{2} \mathrm{H}_{6}, \mathrm{C}_{2} \mathrm{H}_{4}$, $\mathrm{C}_{2} \mathrm{H}_{2}, \mathrm{C}_{3} \mathrm{H}_{8}, \mathrm{C}_{3} \mathrm{H}_{6}$, and $\mathrm{C}_{3} \mathrm{H}_{4}$ molecules interacting with the Na-ETS-10 model are shown in Figures $2-7$, respectively. Additional structural details are provided as Electronic Supplementary Material. Visual inspection of these figures shows that the paraffins, olefins and acetylenes interact with the $\mathrm{Na} 2$ ion (c.f. Figure 1) through their $\mathrm{C}-\mathrm{C}, \mathrm{C}=\mathrm{C}$ or $\mathrm{C} \equiv \mathrm{C}$ bonds, respectively. Carbon atoms in the alkene and alkyne compounds are nearly equidistant to the $\mathrm{Na} 2$ cation (Table 1), which suggests they are forming $\pi$-complexes upon interaction with NaETS-10. Notice that the carbon-carbon bonds in propene and propyne are slightly tilted (i.e., small differences between $\mathrm{Na} 2-\mathrm{C} 1$ and $\mathrm{Na} 2-\mathrm{C} 2$ distances) for better accommodation of the terminal methyl group. Still, significantly larger tilting of the C-C bond is observed for ethane and propane with differences between $\mathrm{Na} 2-\mathrm{C} 1$ and $\mathrm{Na} 2-\mathrm{C} 2$ lengths larger than $0.3 \AA$. From the data compiled in Table 1, it is found that the mean value for the Na2-C1 and Na2-C2 distances decreases with the degree of unsaturation of the $\mathrm{C} 1-\mathrm{C} 2$ bond, i.e., it decreases in the order 
alkanes $>$ alkenes $>$ alkynes, from $\sim 3.0 \AA$ to $\sim 2.8 \AA$. Despite the different proximities of the adsorbates to the $\mathrm{Na} 2$ ion, it becomes clear that the position of the $\mathrm{Na} 2$ ion is negligibly affected by interaction with the sorbates. In fact, $\mathrm{Na} 2$ moves only slightly from its original location in the bare Na-ETS-10 model (Table 1).

The enthalpies calculated for the interaction of the different hydrocarbons with Na-ETS-10 are compiled in Table 2. As it can be seen, they span a range of values between $-26.9 \mathrm{~kJ} \cdot \mathrm{mol}^{-1}$ $\left(\mathrm{C}_{2} \mathrm{H}_{6}\right)$, and $-49.3 \mathrm{~kJ} \cdot \mathrm{mol}^{-1}\left(\mathrm{C}_{2} \mathrm{H}_{2}\right)$ in the case of the $\mathrm{C}_{2} \mathrm{H}_{\mathrm{x}}$ hydrocarbons, and between -42.9 $\mathrm{kJ} \cdot \mathrm{mol}^{-1}\left(\mathrm{C}_{3} \mathrm{H}_{8}\right)$ and $-63.2 \mathrm{~kJ} \cdot \mathrm{mol}^{-1}\left(\mathrm{C}_{3} \mathrm{H}_{4}\right)$ in the case of the $\mathrm{C}_{3} \mathrm{H}_{\mathrm{x}}$ hydrocarbons. The interaction enthalpy increases in the order $\mathrm{CH}_{4}<\mathrm{C}_{2} \mathrm{H}_{\mathrm{x}}<\mathrm{C}_{3} \mathrm{H}_{\mathrm{x}}$, i.e., it becomes more negative with the increase of the number of carbon atoms and from paraffins to olefins to acetylenes. Interestingly, the interaction enthalpies for the acetylenes in Na-ETS-10 are $\sim 20 \mathrm{~kJ} \cdot \mathrm{mol}^{-1}$ larger (i.e. more negative) than those calculated for their paraffin analogues. Also interesting, the difference between the interaction enthalpies for $\mathrm{C}_{3} \mathrm{H}_{8}$ and $\mathrm{C}_{2} \mathrm{H}_{6}$ paraffins, for $\mathrm{C}_{3} \mathrm{H}_{6}$ and $\mathrm{C}_{2} \mathrm{H}_{4}$ olefins and for $\mathrm{C}_{3} \mathrm{H}_{4}$ and $\mathrm{C}_{2} \mathrm{H}_{2}$ acetylenes is $\sim 14 \pm 1 \mathrm{~kJ} \cdot \mathrm{mol}^{-1}$ (Table 2). This suggests that the enthalpic contributions of the single, double and triple bonds interacting with the Na2 ion are $\sim-26, \sim-36$ and $\sim-49 \mathrm{~kJ} \cdot \mathrm{mol}^{-1}$, respectively, and that the difference between interaction enthalpies for $\mathrm{C}_{3} \mathrm{H}_{\mathrm{x}}$ and $\mathrm{C}_{2} \mathrm{H}_{\mathrm{x}}$ hydrocarbons is due to an additional enthalpic contribution of $\sim-14 \mathrm{~kJ} \cdot \mathrm{mol}^{-1}$ resulting from the interaction between the terminal $\mathrm{CH}_{3}$ group in the longer $\mathrm{C}_{3} \mathrm{H}_{\mathrm{x}}$ hydrocarbons and the Na-ETS-10 material. This contribution mainly arises from dispersion interactions between the aliphatic group and the framework atoms as will be shown in the next section. 
(a)

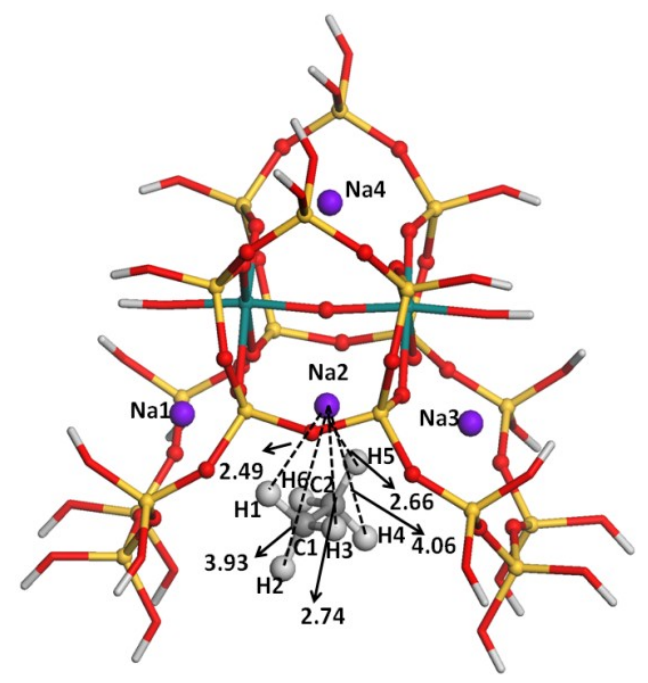

(b)

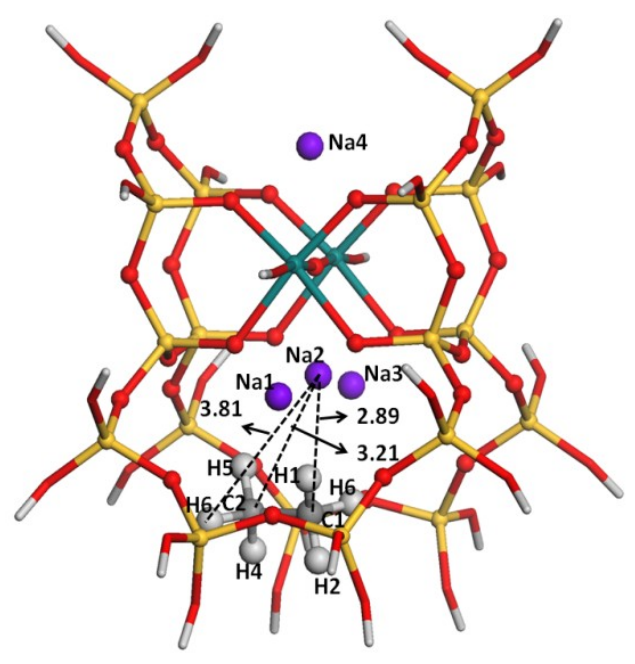

Fig. 2 Configurations optimized with the M06-L/6-31++G** approach and the counterpoise method for $\mathrm{C}_{2} \mathrm{H}_{6}$ interacting with Na-ETS-10, viewed along directions parallel (a) and normal (b) to the - Ti-O-Ti- chain. Dashed lines show the distances between the sodium cation and each individual atom of the sorbate. Color code is the same as in Figure 1.

(a)

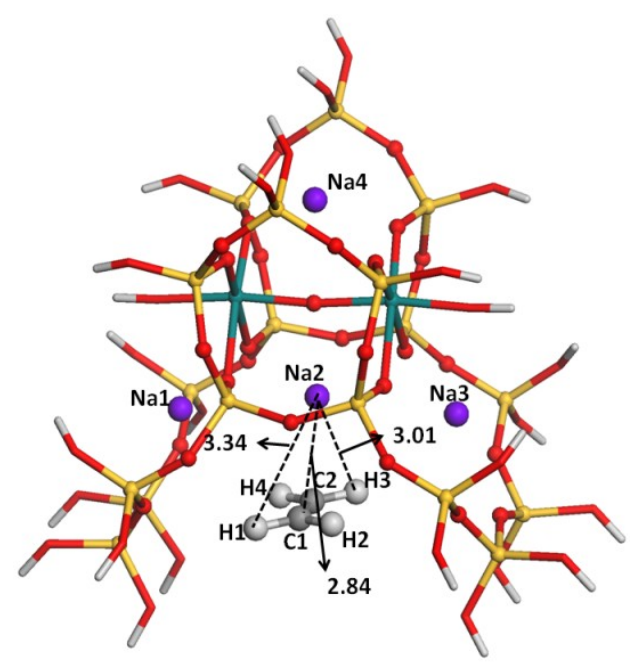

(b)

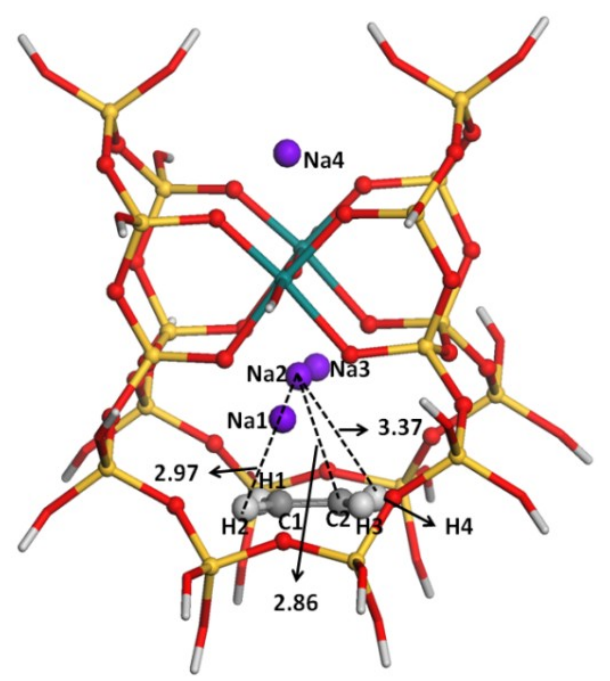

Fig. 3 Configurations optimized with the M06-L/6-31++G** approach and the counterpoise method for $\mathrm{C}_{2} \mathrm{H}_{4}$ interacting with Na-ETS-10, viewed along directions parallel (a) and normal (b) to the - Ti-O-Ti- chain. Dashed lines show the distances between the sodium cation and each individual atom of the sorbate. Color code is the same as in Figure 1. 
(a)

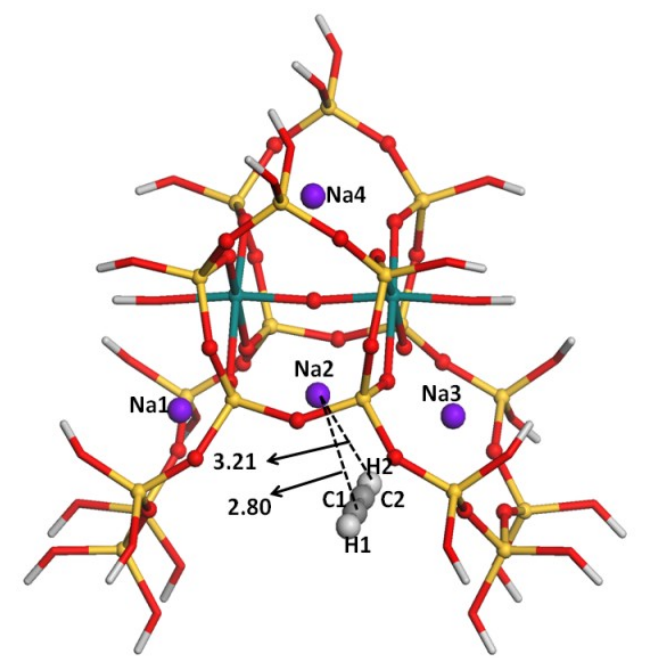

(b)

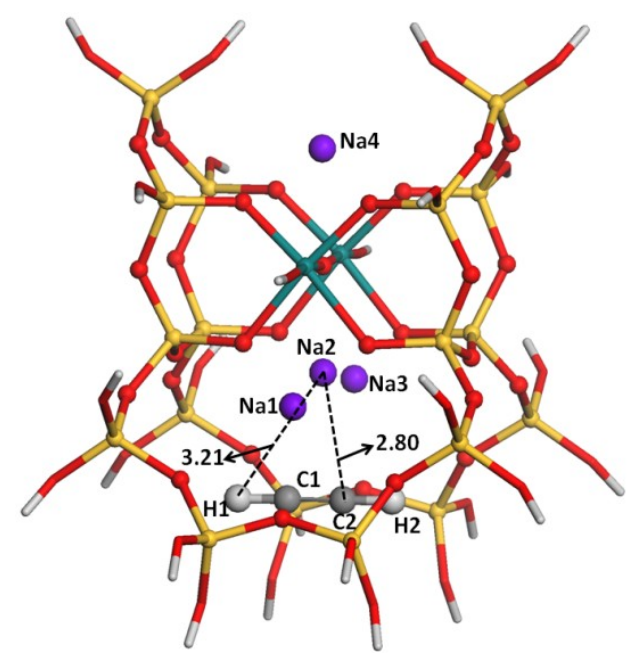

Fig. 4 Configurations optimized with the M06-L/6-31++G** approach and the counterpoise method for $\mathrm{C}_{2} \mathrm{H}_{2}$ interacting with Na-ETS-10, viewed along directions parallel (a) and normal (b) to the - Ti-O-Ti- chain. Dashed lines show the distances between the sodium cation and each individual atom of the sorbate. Color code is the same as in Figure 1.

(a)

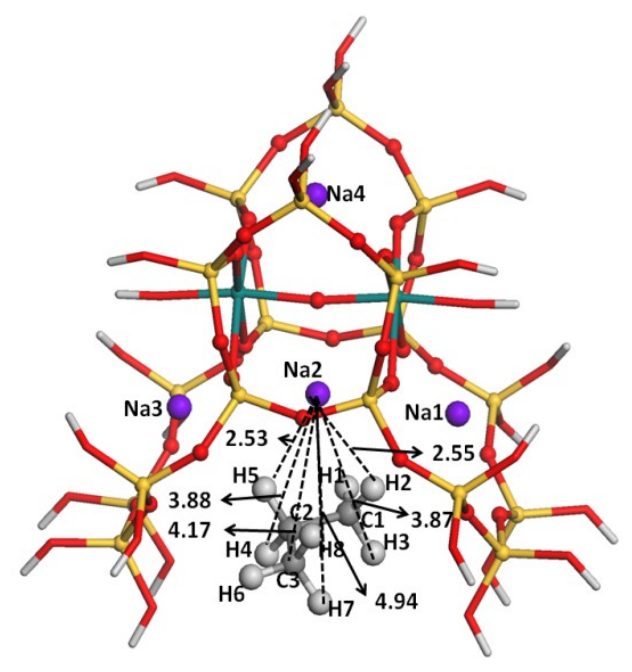

(b)

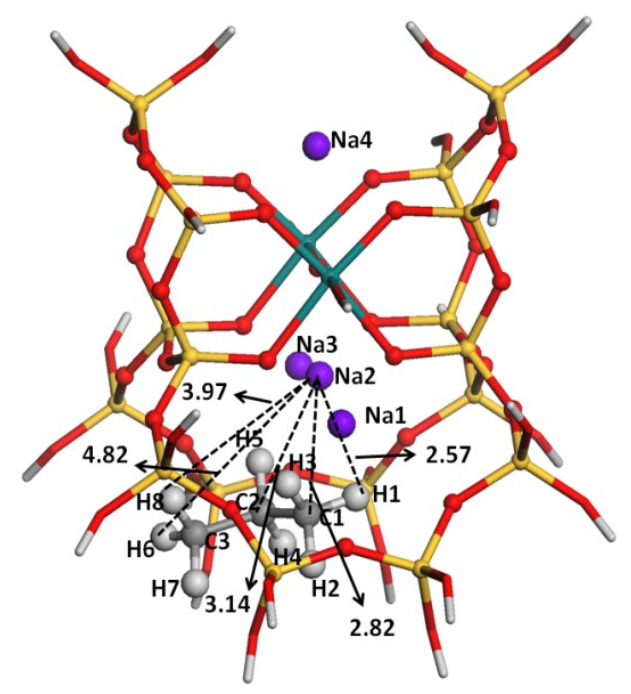

Fig. 5 Configurations optimized with the M06-L/6-31++G** approach and the counterpoise method for $\mathrm{C}_{3} \mathrm{H}_{8}$ interacting with Na-ETS-10, viewed along directions parallel (a) and normal (b) to the - Ti-O-Ti- chain. Dashed lines show the distances between the sodium cation and each individual atom of the sorbate. Color code is the same as in Figure 1. 
(a)

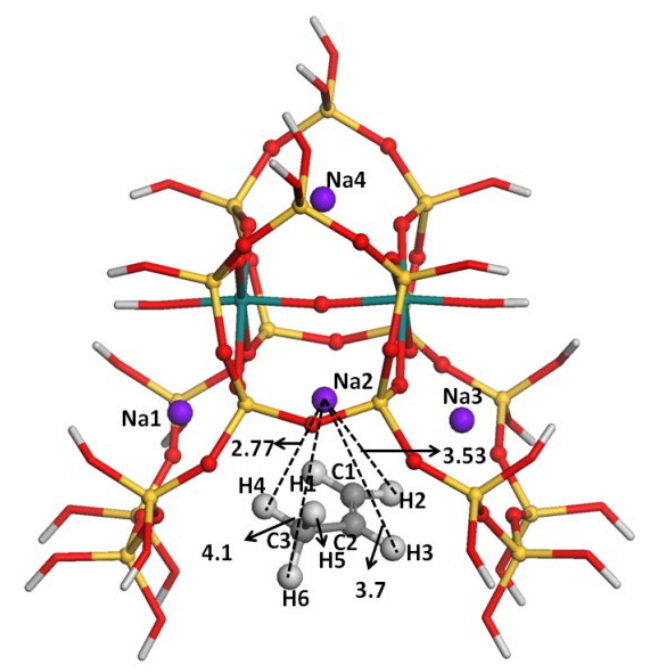

(b)

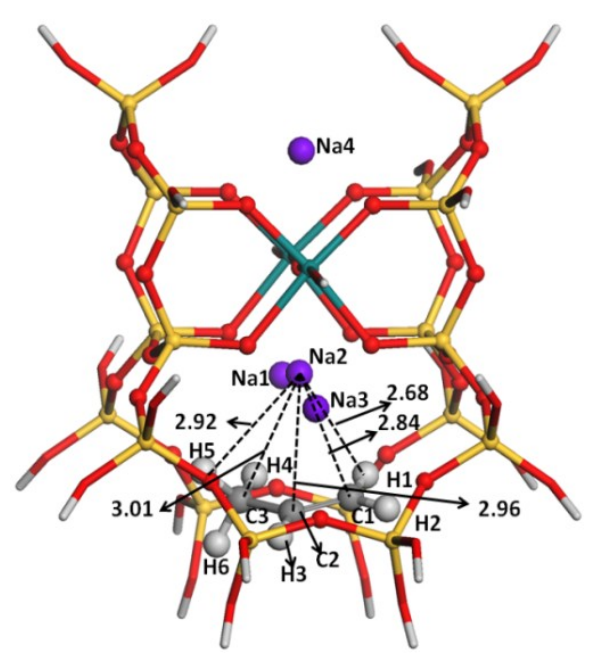

Fig. 6 Configurations optimized with the M06-L/6-31++G** approach and the counterpoise method for $\mathrm{C}_{3} \mathrm{H}_{6}$ interacting with Na-ETS-10, viewed along directions parallel (a) and normal (b) to the - Ti-O-Ti- chain. Dashed lines show the distances between the sodium cation and each individual atom of the sorbate. Color code is the same as in Figure 1.

(a)

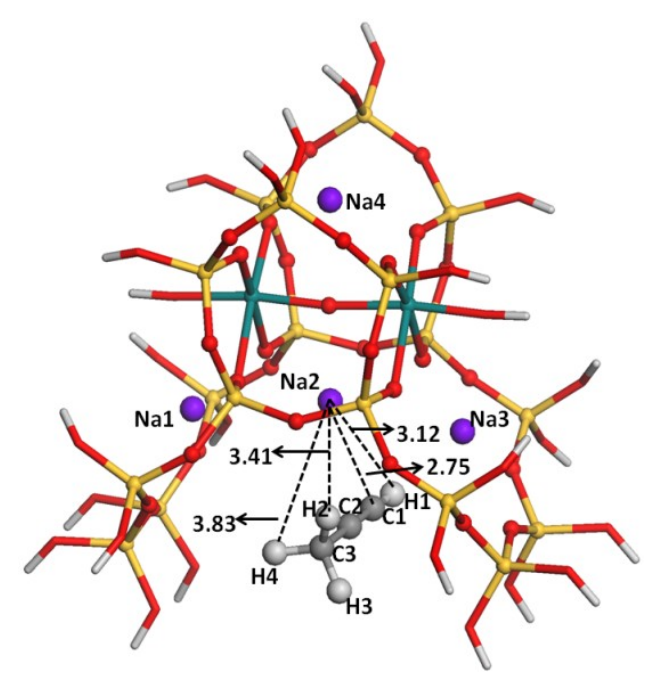

(b)

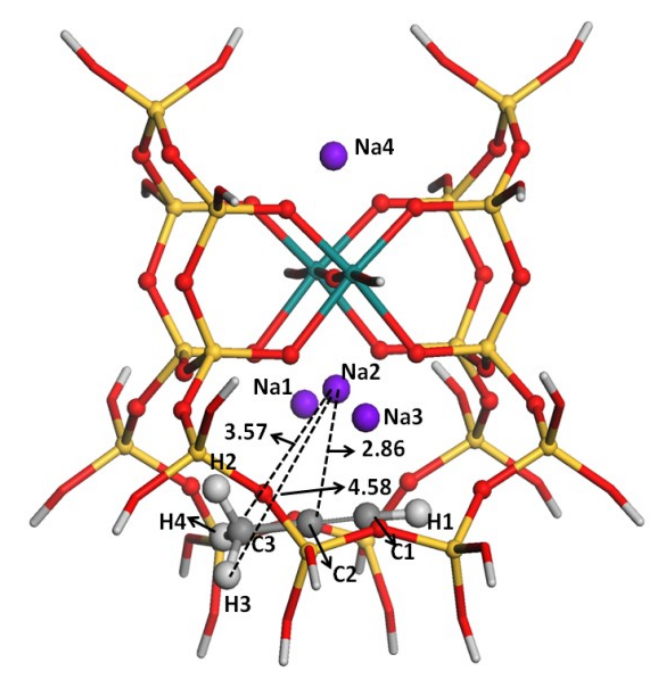

Fig. 7 Configurations optimized with the M06-L/6-31++G** approach and the counterpoise method for $\mathrm{C}_{3} \mathrm{H}_{4}$ interacting with Na-ETS-10, viewed along directions parallel (a) and normal (b) to the - Ti-O-Ti- chain. Dashed lines show the distances between the sodium cation and each individual atom of the sorbate. Color code is the same as in Figure 1. 
Table 1Sodium to hydrocarbon and sodium to framework oxygens distances $(\AA)$ optimized at the M06-L/6-31++G** level of theory using BSSE corrections. ${ }^{\mathrm{a}}$

\begin{tabular}{|l|c|c|c|c|c|c|c|c|}
\hline & Bare & $\mathbf{C H}_{\mathbf{4}}$ & $\mathbf{C}_{\mathbf{2}} \mathbf{H}_{\mathbf{6}}$ & $\mathbf{C}_{\mathbf{2}} \mathbf{H}_{\mathbf{4}}$ & $\mathbf{C}_{\mathbf{2}} \mathbf{H}_{\mathbf{2}}$ & $\mathbf{C}_{\mathbf{3}} \mathbf{H}_{\mathbf{8}}$ & $\mathbf{C}_{\mathbf{3}} \mathbf{H}_{\mathbf{6}}$ & $\mathbf{C}_{\mathbf{3}} \mathbf{H}_{\mathbf{4}}$ \\
\hline $\mathrm{Na} 2-\mathrm{C} 1$ & - & $2.88^{\mathrm{c}}$ & 2.89 & 2.84 & 2.80 & 2.82 & 2.84 & 2.75 \\
\hline $\mathrm{Na} 2-\mathrm{C} 2$ & - & - & 3.21 & 2.86 & 2.80 & 3.14 & 2.96 & 2.86 \\
\hline $\mathrm{Na} 2-\mathrm{C} 3$ & - & - & - & - & - & 4.17 & 4.10 & 3.57 \\
\hline $\mathrm{Na} 2-\mathrm{C}$ & - & - & 3.05 & 2.85 & 2.80 & 2.98 & 2.90 & 2.80 \\
\hline $\mathrm{Na} 2-\mathrm{O} 1$ & 2.42 & $2.42^{\mathrm{c}}$ & 2.40 & 2.41 & 2.41 & 2.40 & 2.42 & 2.41 \\
\hline $\mathrm{Na} 2-\mathrm{O} 2$ & 2.42 & $2.42^{\mathrm{c}}$ & 2.43 & 2.42 & 2.41 & 2.43 & 2.43 & 2.42 \\
\hline $\mathrm{Na} 2-\mathrm{O} 5$ & 2.25 & $2.25^{\mathrm{c}}$ & 2.24 & 2.24 & 2.23 & 2.23 & 2.24 & 2.24 \\
\hline $\mathrm{Na} 2-\mathrm{O} 6$ & 2.42 & $2.42^{\mathrm{c}}$ & 2.43 & 2.41 & 2.43 & 2.43 & 2.41 & 2.42 \\
\hline $\mathrm{Na} 2-\mathrm{O} 7$ & 2.42 & $2.42^{\mathrm{c}}$ & 2.41 & 2.42 & 2.43 & 2.41 & 2.41 & 2.44 \\
\hline
\end{tabular}

${ }^{\mathrm{a}}$ Data calculated with the M06-L/6-31G** approach is almost indistinguishable. ${ }^{\mathrm{b}}$ Mean value of $\mathrm{Na} 2-\mathrm{C} 1$ and Na2-C2 distances. ${ }^{\mathrm{c}}$ Data from ref.[21].

Table 2 Comparison between the experimental isosteric heats of adsorption $\left(\Delta H^{\text {isosteric }}\right)$ and the calculated energies $(\Delta E)$ or enthalpies of interaction $\left(\Delta H^{T \mathrm{~K}}\right)$ at temperatures $T=0 \mathrm{~K}$ or $298.15 \mathrm{~K}$. All values in $\mathrm{kJ} \cdot \mathrm{mol}^{-1}$.

\begin{tabular}{|c|c|c|c|c|}
\hline Hydrocarbon & $\boldsymbol{\Delta} \boldsymbol{H}^{\text {isosteric }}$ & $\boldsymbol{\Delta}$ & $\boldsymbol{\Delta} \boldsymbol{H}^{\mathbf{0 K}}$ & $\boldsymbol{\Delta}^{\mathbf{2 9 8 . 1 5 K}}$ \\
\hline $\mathrm{CH}_{4}$ & $-21.4^{\mathrm{b}},-21.0^{\mathrm{c}},-20.8^{\mathrm{d}},-23.3^{\mathrm{e}}$ & $-27.4(-27.7)$ & $-20.2(-20.3)$ & $-20.8(-20.9)$ \\
\hline $\mathrm{C}_{2} \mathrm{H}_{6}$ & $-35.4^{\mathrm{b}},-34.7^{\mathrm{c}},-33.8^{\mathrm{d}},-34.8^{\mathrm{f}}$ & $-34.4(-35.1)$ & $-26.5(-26.9)$ & $-26.9(-28.0)$ \\
\hline $\mathrm{C}_{2} \mathrm{H}_{4}$ & $-42.8^{\mathrm{b}},-39.6^{\mathrm{c}},-34.3^{\mathrm{d}},-49.7^{\mathrm{f}}$, & $-42.4(-43.3)$ & $-36.1(-36.3)$ & $-35.8(-36.2)$ \\
\hline $\mathrm{C}_{2} \mathrm{H}_{2}$ & $-33.8^{\mathrm{g}}$ & $-54.5(-55.6)$ & $-48.8(-50.0)$ & $-49.3(-50.5)$ \\
\hline $\mathrm{C}_{3} \mathrm{H}_{8}$ & & $-50.3(-51.2)$ & $-42.1(-42.9)$ & $-42.1(-42.9)$ \\
\hline $\mathrm{C}_{3} \mathrm{H}_{6}$ & & $-58.1(-59.1)$ & $-50.6(-51.9)$ & $-50.5(-51.7)$ \\
\hline $\mathrm{C}_{3} \mathrm{H}_{4}$ & & $-69.9(-70.7)$ & $-62.1(-62.6)$ & $-62.8(-63.2)$ \\
\hline
\end{tabular}

${ }^{\mathrm{a}}$ Data in parenthesis were calculated with the M06-L/6-31G** approach while the remaining values were obtained at the M06-L/6-31++ $\mathrm{G}^{* *}$ level of theory; interaction energies and enthalpies include BSSE corrections; calculated data for $\mathrm{CH}_{4}$ was taken from ref.[21]. ${ }^{\mathrm{b}-\mathrm{g}}$ Available experimental enthalpies of interaction are: ${ }^{\mathrm{b}}$ Toth model, ref.[18]; ${ }^{\mathrm{c}}$ unilan model, ref.[18]; ${ }^{\mathrm{d}}$ virial three constants model, ref.[18]; ${ }^{\mathrm{e}}$ Toth model, ref.[41]; ${ }^{\mathrm{f}}$ Langmuir model, ref. [41]; 'unilan model,ref. [15]. 
The calculated enthalpies at $T=298.15 \mathrm{~K}$ for $\mathrm{C}_{2} \mathrm{H}_{6}$ and $\mathrm{C}_{2} \mathrm{H}_{4}$ adsorption on Na-ETS- 10 compare well with the experimental isosteric heats available in the literature, although some degree of underestimation is observed, particularly for ethane. In the latter case, the difference between the calculated and the mean value of the experimental data is $8 \mathrm{~kJ} \cdot \mathrm{mol}^{-1}$ and our calculated value lies below the smallest reported adsorption enthalpy. Although this may suggest that calculations aresomewhat underestimating dispersion interactions with the framework, it is also important to note that the experimental results were derived from fits using different models and, therefore, are expected to have rather high associated uncertainties. This is even more evident for ethene, where the difference between the least and mostnegative experimental isosteric heats reported is $16 \mathrm{~kJ} \cdot \mathrm{mol}^{-1}$. For this molecule, the difference between the calculated and the mean value of the experimental data is $4 \mathrm{~kJ} \cdot \mathrm{mol}^{-1}$, and our DFT result lies well within the range of variability of experimental values. Our results predict a significantly stronger adsorption enthalpy for ethene compared to ethane (by about $-9 \mathrm{~kJ} \cdot \mathrm{mol}^{-1}$ ), which agrees with the differences observed in each individual experimental study $[18,41]$. The only exception is the virial three constants model fit for ethane and ethene[18], wheresimilar isosteric heats were predicted, which is not in line with the type of interaction with the sodium ion expected for each of these two sorbates. In fact, the shapes of the experimental adsorption isotherms for ethene and ethane [41] show that ethene adsorbs more than ethane in all pressure range.This again emphasizes the high degree of uncertainty in the experimental estimates.Interestingly, Al-Baghli et al. conclude their work by suggesting that the virial three constants modelappears to be the best model for deducing the true Henry's constant information [18]. In fact, the estimates with the virial three constants model are those comparing better with the DFT enthalpies of adsorption despite the small underestimation in the case of ethane. Notice also that in our previous work [21], the 
enthalpy for nitrogen interaction with Na-ETS-10 calculated with the same cluster model and DFT approach compared well with the available experimental result while a noticeable underestimation $\left(\sim 7 \mathrm{~kJ} \cdot \mathrm{mol}^{-1}\right.$ with the M06-L/6-31++ $\mathrm{G}^{* *}$ approach and $\sim 3 \mathrm{~kJ} \cdot \mathrm{mol}^{-1}$ with the M06-L/6-31G** approach) was found in the case of carbon dioxide. Note however that the experimental result for carbon dioxide was determined by the same authors reporting the largest value $\left(-49.7 \mathrm{~kJ} \cdot \mathrm{mol}^{-1}\right)$ for ethene interaction with Na-ETS-10 [36]. This suggests that the much more negative isosteric heats reported by Shi et al. [36] may be due to the presence of other cations than $\mathrm{Na}^{+}$in the Na-ETS-10 sample, which interact strongerthan $\mathrm{Na}$ cations with $\mathrm{CO}_{2}$ and with the double bond in ethene. The verification of this hypothesis needs further experimental work and we hope that the present and previous [21] studies on the interaction of gaseous molecules with Na-ETS-10 can trigger such experiments.

It is interesting to notice that our calculated enthalpic data for methane, ethane and ethene are very close to the experimental isosteric heats reported by Ruthven et al.[56] for adsorption in sodium-containing 5A zeolite, respectively, $-21.8,-27.6$ and $-33.5 \mathrm{~kJ} \cdot \mathrm{mol}^{-1}[56,57]$, where a similar adsorption mechanism is anticipated for these small sorbates. This fact, together with the very good agreement between calculated enthalpies of interaction and experimental heats of adsorption reported in ref. [21] for $\mathrm{N}_{2}, \mathrm{CH}_{4}$, and $\mathrm{CO}_{2}$, and in Table 2 for $\mathrm{C}_{2} \mathrm{H}_{4}$, give us confidence that the accuracy of our calculated interaction enthalpies for the other $\mathrm{C}_{2} \mathrm{H}_{\mathrm{x}}$ and $\mathrm{C}_{3} \mathrm{H}_{\mathrm{x}}$ hydrocarbons in Na-ETS-10, for which experimental heats of adsorption are not available, is also high. Furthermore, the result calculated for ethyne interacting with the Na2 site of Na-ETS-10, $49.3 \mathrm{~kJ} \cdot \mathrm{mol}^{-1}$, is close to the value reported by Guo et al. [22], $-46 \mathrm{~kJ} \cdot \mathrm{mol}^{-1}$, calculated with the same functional employed in this work but with a different cluster model. 
The separation of unsaturated hydrocarbons from their saturated counterparts is mostly determined by its $\pi$-complexation capacity on the adsorbent. The extra-framework cations present in Na-ETS-10 could enhance the $\pi$-complexation capacity of unsaturated hydrocarbons. The present DFT study indeed suggests that the strength of the adsorption of hydrocarbons in Na-ETS-10 depends on the unsaturation and the bulkiness of the hydrocarbon, i.e the enthalpies of interaction in Na-ETS-10 increase in the order of $\mathrm{CH}_{4}<\mathrm{C}_{2} \mathrm{H}_{\mathrm{x}}<\mathrm{C}_{3} \mathrm{H}_{\mathrm{x}}$ as well as in the order C-C $<\mathrm{C}=\mathrm{C}<\mathrm{C} \equiv \mathrm{C}$ (for hydrocarbons with the same number of carbon atoms).

\subsection{Population and Topological Analyses}

A natural population analysis (NPA) has been performed for the complexes between NaETS-10 and the different hydrocarbons. The NPA charges for the Na2 ion and for the hydrocarbons are reported in Table 3. As it can be seen, the overall charge on the adsorbates is always positive while in the $\mathrm{Na} 2$ ion it is less positive than in the bare system $(0.801 e$ e, c.f. Table 3 footnote), which indicates some electron transfer from the adsorbate to the cation. Upon adsorption, the framework oxygen atoms neighboring $\mathrm{Na} 2$ also donate some charge to this cation (not shown).

The intramolecular bonding between the hydrocarbons and the Na-ETS-10 cluster model was analyzed with the atoms in molecules (AIM) [58] and electron localization function (ELF) $[59,60]$ approaches. The AIM analyses revealed bond critical points (BCP), i.e., points where the gradient of the electron density is null, in regions between the hydrocarbon and the $\mathrm{Na} 2$ ion. The electron densities at the BCP and their Laplacians, closely related to bonding strength and bonding type, respectively, are compiled in Table 3. Briefly, weak interactions are denoted by 
small values of the electron density at the BCP, e.g. electron densities between $\sim 0.05 e \mathrm{e}_{0}{ }^{-3}$ and $0.01 e \mathrm{a}_{0}{ }^{-3}$ in the case of hydrogen bonds and below $\sim 0.01 e \mathrm{a}_{0}^{-3}$ in the case of van der Waals interactions; negative values of the Laplacian at the $\mathrm{BCP}$ indicate a covalent bond, while positive values indicate an ionic bond or a van der Waals interaction [58]. Based on this classification, we can say that the topology shows a weak character for the interactions between the different hydrocarbons considered in this work and the $\mathrm{Na} 2$ ion. Still, the values at the critical points for the electron density and for the electron localization function are larger in the unsaturated than in the saturated hydrocarbons, which is in line with the calculated interaction enthalpies reported in Table 2.

Table 3 Calculated natural charges, $q$, for the Na2 cation and for the sorbate, electron density, $\rho$, Laplacian of the electron density, $\nabla^{2} \rho$, and electron localization function, ELF, for hydrocarbons interacting with Na-ETS- 10 .

\begin{tabular}{|c|c|c|c|c|c|}
\hline Hydrocarbon & $\boldsymbol{q}_{\mathbf{N a 2}}{ }^{a}(\boldsymbol{e})$ & $\boldsymbol{q}_{\text {sorbate }}(\boldsymbol{e})$ & $\boldsymbol{\rho}\left(\boldsymbol{e a}_{\mathbf{0}}{ }^{-\mathbf{3}}\right)$ & $\nabla^{2} \boldsymbol{\rho}\left(\boldsymbol{e \mathbf { a } _ { \mathbf { 0 } }}{ }^{-\mathbf{3}}\right)$ & $\mathbf{E L F}$ \\
\hline $\mathrm{CH}_{4}$ & 0.728 & 0.029 & 0.005 & 0.031 & 0.004 \\
\hline $\mathrm{C}_{2} \mathrm{H}_{6}$ & 0.690 & 0.049 & 0.006 & 0.036 & 0.007 \\
\hline $\mathrm{C}_{2} \mathrm{H}_{4}$ & 0.691 & 0.052 & 0.009 & 0.040 & 0.019 \\
\hline $\mathrm{C}_{2} \mathrm{H}_{2}$ & 0.705 & 0.044 & 0.010 & 0.048 & 0.018 \\
\hline $\mathrm{C}_{3} \mathrm{H}_{8}$ & 0.672 & 0.056 & 0.007 & 0.039 & 0.008 \\
\hline $\mathrm{C}_{3} \mathrm{H}_{6}$ & 0.649 & 0.072 & 0.008 & 0.037 & 0.015 \\
\hline $\mathrm{C}_{3} \mathrm{H}_{4}$ & 0.691 & 0.040 & 0.010 & 0.048 & 0.019 \\
\hline
\end{tabular}

${ }^{\mathrm{a}}$ For atomic labelling please refer to Figure $2 ; \mathrm{q}_{\mathrm{Na} 2}$ in bare cluster model is 0.801 a.u. 


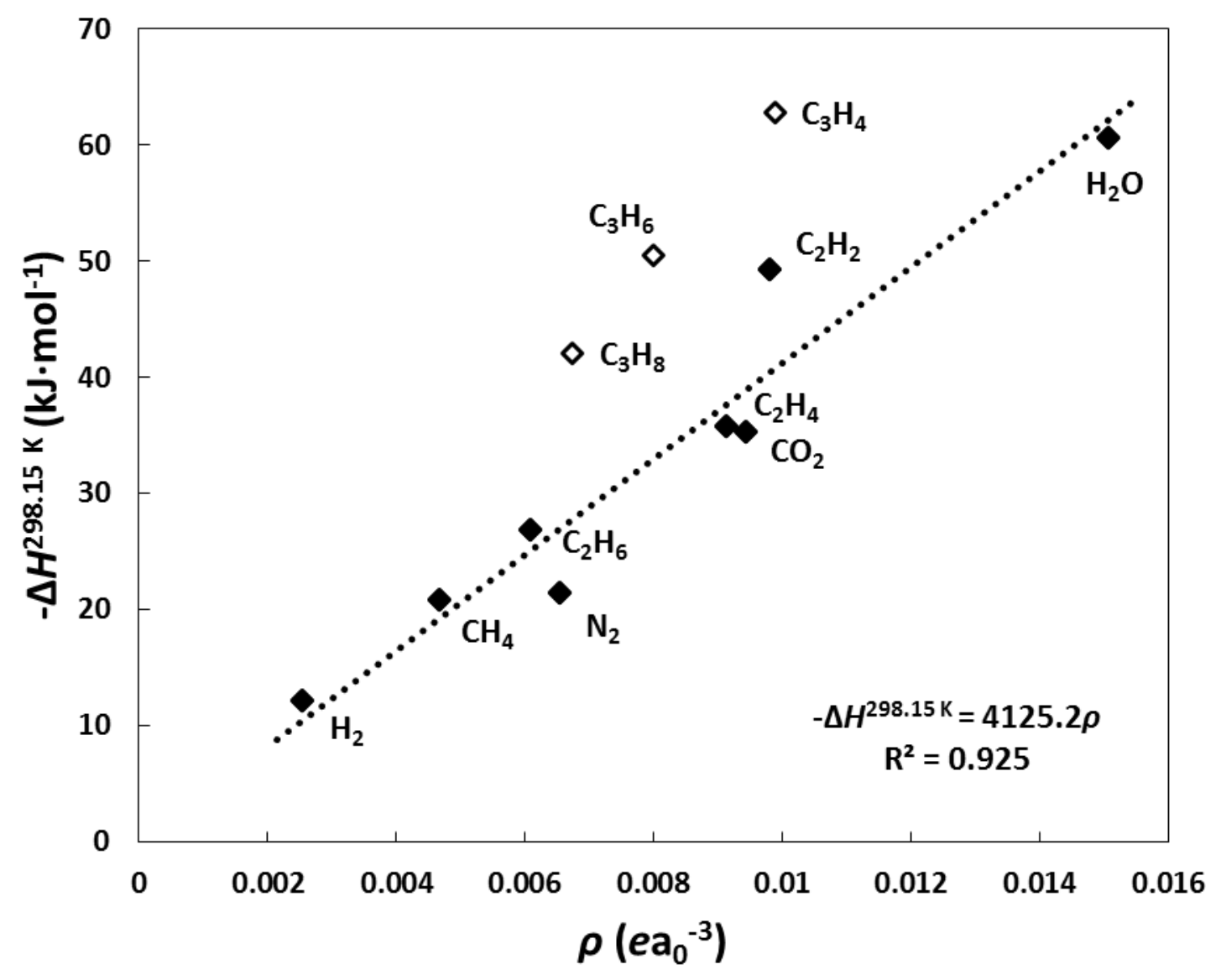

Fig. 8 Variation of the enthalpy for the interaction between different sorbatesand Na-ETS-10 withthe corresponding electron densities at the bond critical points in the region between the sorbates and the $\mathrm{Na} 2$ ion. Equation and trendline were adjusted with data for species marked with filled diamondsand by setting the intercept to zero. Notice that the enthalpies were multiplied by -1 . 
The values of the electron density at the $\mathrm{BCP}$ can be used to analyze if the sorbatesubstrate interactions are quite localized and involve mainly the interaction with sodium ion $\mathrm{Na} 2$. A graphical representation corresponding to the relationship between the enthalpies of interaction and the electron density at the $\mathrm{BCP}$ in the region between the adsorbate and the $\mathrm{Na} 2$ ion is shown in Figure 8. Data from our previous study concerning the interaction of atmospheric gases with the same Na-ETS-10 model [21]are also included in the plot. There is a quite clear correlation between the calculated values of the enthalpies of interaction and the electron densities for the smaller adsorbates, e.g. filled marks in Figure 8, which suggests negligible interaction between the sorbates and the Na-ETS-10 framework atoms composing the 12-MR (i.e., adsorption is largely dominated by specific interactions with the Na cation). The electron densities at the $\mathrm{BCP}$ are less correlated with the enthalpies of interaction calculated for the larger sorbates in Figure 8, i.e., $\mathrm{C}_{3} \mathrm{H}_{\mathrm{x}}$ hydrocarbons, suggesting that the interaction with Na-ETS-10 is much stronger than expected from just the values of the electron densities. Therefore, the adsorption of the $\mathrm{C}_{3} \mathrm{H}_{\mathrm{x}}$ hydrocarbons is still dominated by the interaction with the $\mathrm{Na} 2$ ion but interaction with framework atoms is also contributing to the stabilization of the $\mathrm{C}_{3} \mathrm{H}_{\mathrm{x}}$ hydrocarbons inside the 12-MR pores. We have searched for additional $\mathrm{BCP}$ that could be responsible for such additional stabilization and found that the hydrogen atoms of the terminal methyl group are establishing weak but important contacts with the Na-ETS-10 framework (Figure S1). Such contacts are more relevant in the case of propyne, i.e., the values of the electron density at the $\mathrm{BCP}$ are larger than in propene and propane. The electron densities corresponding to the $\mathrm{BCP}$ involving the methyl group decrease in the order propyne> propene $>$ propane, which is in very good agreement with the ordering of the deviations between the corresponding points and trendline in Figure 8. 
These findings are in line with the discussion in the preceding section suggesting enthalpic contributions of the single, double and triple bonds for the interaction between hydrocarbons and the Na2 ion of $\sim-26, \sim-36$ and $\sim-49 \mathrm{~kJ} \cdot \mathrm{mol}^{-1}$, respectively, and an additional enthalpic contribution of $\sim 14 \mathrm{~kJ} \cdot \mathrm{mol}^{-1}$ from interactions with the framework. Encouragingly, the correlation coefficient when considering all the data points in Figure 8 changes from 0.686 ($\left.\Delta H^{298.15 \mathrm{~K}}=4686 \rho\right)$ to $0.904\left(-\Delta H^{298.15 \mathrm{~K}}=4260 \rho\right)$ if the enthalpies for the $\mathrm{C}_{3} \mathrm{H}_{\mathrm{x}}$ hydrocarbons (open symbols in Figure 8) are subtracted by $-14 \mathrm{~kJ} \cdot \mathrm{mol}^{-1}$, further supporting our conclusions (Figure S2 in the Electronic Supplementary Material).

\subsection{Vibrational Frequencies for Gaseous hydrocarbons in ETS-10}

According to recent DFT work performed at the M06-L/6-31++G(d,p) level of theory and employing the same Na-ETS-10 cluster model used in the present work [21], characteristic Si-O and Ti-O stretching vibrational modes in experimental vibrational results of ETS-10 [22, 61, 62] are well reproduced by the calculations. Additionally, vibrational frequencies for isolated and for adsorbed $\mathrm{CH}_{4}, \mathrm{H}_{2}, \mathrm{~N}_{2}, \mathrm{CO}_{2}$ and $\mathrm{H}_{2} \mathrm{O}$ species also compared well with available experimental results by correcting the vibrational modes above $1000 \mathrm{~cm}^{-1}$ using a scale factor[63], e.g. 0.949 , obtained by minimization of the sum of the differences between scaled and experimental vibrations for the five gases[21]. The same computational strategy was followed in this work to calculate the vibrational frequencies for the hydrocarbons adsorbed in Na-ETS-10 (Table 4) and isolated in vacuum (Tables S3-S8).As it can be seen in Table 4, scaled frequencies for the different hydrocarbons interacting with Na-ETS-10 compare well with available IR absorption bands, although larger differences arise from consideration of impure Na-ETS-10 samples or formation of conjugated carbocationic (charged) species [58] in the experimental studies. This 
confirms that the experimental vibrations are due to the formation of $\mathrm{Na}^{+} \cdots$ hydrocarbon (i.e, $\mathrm{C}_{2} \mathrm{H}_{6}, \mathrm{C}_{2} \mathrm{H}_{4}, \mathrm{C}_{2} \mathrm{H}_{4}, \mathrm{C}_{3} \mathrm{H}_{8}, \mathrm{C}_{3} \mathrm{H}_{6}$, or $\mathrm{C}_{3} \mathrm{H}_{4}$ ) adducts with $\mathrm{Na}$ cations located in the 12-membered channels, and that the model with two titanium (2Ti) and four extra-framework sodium ions at their two cation locations is able to accurately describe the adsorption properties of hydrocarbon interaction in ETS-10 materials.

\section{Conclusions}

The interactions of $\mathrm{C}_{2} \mathrm{H}_{6}, \mathrm{C}_{2} \mathrm{H}_{4}, \mathrm{C}_{2} \mathrm{H}_{4}, \mathrm{C}_{3} \mathrm{H}_{8}, \mathrm{C}_{3} \mathrm{H}_{6}$, and $\mathrm{C}_{3} \mathrm{H}_{4}$ species with ETS-10 having extra framework sodium cations were studied by means of density functional theory. Calculated enthalpies for the interaction of these gaseous hydrocarbons with Na-ETS-10 are in good agreement with available experimental isosteric heats of adsorption. The strength of the hydrocarbon-material interaction increases with the increase in the number of carbon atoms and in the order paraffins $<$ olefins $<$ acetylenes, with enthalpies of interaction at $T=298.15 \mathrm{~K}$ ranging between $-26.5 \mathrm{~kJ} \cdot \mathrm{mol}^{-1}\left(\mathrm{C}_{2} \mathrm{H}_{6}\right)$ and $-63.3 \mathrm{~kJ} \cdot \mathrm{mol}^{-1}\left(\mathrm{C}_{3} \mathrm{H}_{4}\right)$. From topological analyses and from the comparison of calculated and experimental vibrational frequencies it was concluded that the adsorbates interact preferentially with the sodium cation located in the large 12-membered ring of ETS-10. It is suggested that for the larger $\mathrm{C}_{3} \mathrm{H}_{\mathrm{x}}$ species, van der Waals interactions between the terminal methyl group and the ETS-10 walls also contribute to sorbate-substrate stabilization; the latter contribution seems to be of minor importance in the cases of methane and of the $\mathrm{C}_{2} \mathrm{H}_{\mathrm{x}}$ hydrocarbons. 
Table 4.Relevant calculated vibrational frequencies $\left(\mathrm{cm}^{-1}\right)$ for different adsorbed hydrocarbons in Na-ETS-10.

\begin{tabular}{|c|c|c|c|c|}
\hline \multirow[t]{2}{*}{ Hydrocarbon } & \multicolumn{2}{|c|}{ Calculated } & \multicolumn{2}{|l|}{ Experimental } \\
\hline & Unscaled & Scaled $^{\mathrm{a}}$ & Bands & Ref. \\
\hline \multirow{3}{*}{$\mathrm{C}_{2} \mathrm{H}_{6}$} & $3166-3030\left(v_{\mathrm{C}-\mathrm{H}}\right)$ & $3004-2875\left(v_{\mathrm{C}-\mathrm{H}}\right)$ & & \\
\hline & $1557-1407\left(\delta_{\mathrm{CH} 3}\right)$ & $1477-1335\left(\delta_{\mathrm{CH} 3}\right)$ & & \\
\hline & $1229-1201\left(v_{\mathrm{C}-\mathrm{C}}\right)$ & $1166-1140\left(v_{\mathrm{C}-\mathrm{C}}\right)$ & & \\
\hline \multirow{5}{*}{$\mathrm{C}_{2} \mathrm{H}_{4}$} & $3249-3138\left(v_{\mathrm{C}-\mathrm{H}}\right)$ & $3082-2977\left(v_{\mathrm{C}-\mathrm{H}}\right)$ & $3084,2998,2970\left(v_{\mathrm{C}-\mathrm{H}}\right)$ & [44] \\
\hline & $1693\left(v_{\mathrm{C}=\mathrm{C}}\right)$ & $1606\left(v_{\mathrm{C}=\mathrm{C}}\right)$ & $1613\left(v_{\mathrm{C}=\mathrm{C}}\right)$ & \\
\hline & $1471-1379\left(\delta_{\mathrm{CH} 2}\right)$ & $1396-1308\left(\delta_{\mathrm{CH} 2}\right)$ & $1444-1338\left(\delta_{\mathrm{CH} 2}\right)$ & \\
\hline & $1234-1113\left(\gamma_{\mathrm{CH} 2}\right)$ & $1171-1056\left(\gamma_{\mathrm{CH} 2}\right)$ & & \\
\hline & $1000-582\left(\gamma_{\mathrm{CH} 2}\right)$ & $1000-582\left(\gamma_{\mathrm{CH} 2}\right)$ & & \\
\hline \multirow{4}{*}{$\mathrm{C}_{2} \mathrm{H}_{2}$} & $3470-3365\left(v_{\mathrm{C}-\mathrm{H}}\right)$ & $3292-3193\left(v_{\mathrm{C}-\mathrm{H}}\right)$ & $3229-3212\left(v_{\mathrm{C}-\mathrm{H}}\right)$ & [22] \\
\hline & $2036\left(v_{\mathrm{C}=\mathrm{C})}\right)$ & $1932\left(v_{\mathrm{C} \equiv \mathrm{C}}\right)$ & & \\
\hline & $1207-1077\left(\delta_{\mathrm{CH}}\right)$ & $1145-1021\left(\delta_{\mathrm{CH}}\right)$ & & \\
\hline & $993\left(\gamma_{\mathrm{CH}}\right)$ & $993\left(\gamma_{\mathrm{CH}}\right)$ & & \\
\hline \multirow{3}{*}{$\mathrm{C}_{3} \mathrm{H}_{8}$} & $3156-3016\left(v_{\mathrm{C}-\mathrm{H}}\right)$ & $2994-2862\left(v_{\mathrm{C}-\mathrm{H}}\right)$ & & \\
\hline & $1537-1336\left(\delta_{\mathrm{CH} 3}\right)$ & $1458-1268\left(\delta_{\mathrm{CH} 3}\right)$ & & \\
\hline & $1228-1201\left(v_{C-C}\right)$ & $1165-1140\left(v_{C-C}\right)$ & & \\
\hline \multirow{7}{*}{$\mathrm{C}_{3} \mathrm{H}_{6}$} & $3255-3044\left(v_{\mathrm{C}-\mathrm{H}}\right)$ & $3088-2888\left(v_{\mathrm{C}-\mathrm{H}}\right)$ & & [64] \\
\hline & $1715\left(v_{\mathrm{C}=\mathrm{C}}\right)$ & $1627\left(v_{\mathrm{C}=\mathrm{C}}\right)$ & $1688\left(v_{\mathrm{C}=\mathrm{C}}\right)^{\mathrm{b}}$ & \\
\hline & $1497-1440\left(\delta_{\mathrm{CH} 3}\right)$ & $1391-1367\left(\delta_{\mathrm{CH} 3}\right)$ & & \\
\hline & $1436-1320\left(\delta_{\mathrm{CH} 2}\right)$ & $1362-1252\left(\delta_{\mathrm{CH} 2}\right)$ & & \\
\hline & $1318-1302\left(\delta_{\mathrm{CH}}\right)$ & $1251-1236\left(\delta_{\mathrm{CH}}\right)$ & & \\
\hline & $1208-1100\left(\gamma_{\mathrm{CH} 2}\right)$ & $1146-1044\left(\gamma_{\mathrm{CH} 2}\right)$ & & \\
\hline & $1006-582\left(v_{\mathrm{C}-\mathrm{C}}\right)$ & $1006-582\left(v_{\mathrm{C}-\mathrm{C}}\right)$ & & \\
\hline \multirow{5}{*}{$\mathrm{C}_{3} \mathrm{H}_{4}$} & $3438-3075\left(v_{\mathrm{C}-\mathrm{H}}\right)$ & $3262-2917\left(v_{\mathrm{C}-\mathrm{H}}\right)$ & $3290\left(v_{\mathrm{C}-\mathrm{H}}\right)^{\mathrm{c}}$ & [64] \\
\hline & $2200\left(v_{\mathrm{C} \equiv \mathrm{C}}\right)$ & $2087\left(v_{\mathrm{C} \equiv \mathrm{C}}\right)$ & $2118\left(v_{\mathrm{C} \equiv \mathrm{C}}\right)^{\mathrm{c}}$ & \\
\hline & $1487-1412\left(\delta_{\mathrm{CH} 3}\right)$ & $1411-1340\left(\delta_{\mathrm{CH} 3}\right)$ & $1447\left(\delta_{\mathrm{CH} 3}\right)^{\mathrm{c}}$ & \\
\hline & $1205-1042\left(\delta_{\mathrm{CH}}\right)$ & $1143-989\left(\delta_{\mathrm{CH}}\right)$ & & \\
\hline & $996\left(v_{C-C}\right)$ & $990\left(v_{C}-C\right)$ & & \\
\hline
\end{tabular}

${ }^{\mathrm{a}} \mathrm{M} 06-\mathrm{L} / 6-31++\mathrm{G}(\mathrm{d}, \mathrm{p})$ level of theory; scale factor for vibrations above $1000 \mathrm{~cm}^{-1}$ is 0.949 while vibrations below are unscaled; ${ }^{\mathrm{b}}$ Value obtained from $\mathrm{CH}_{3} \mathrm{C}_{2} \mathrm{H}_{2}{ }^{+}$monomer; ${ }^{\mathrm{c}}$ Vibrations for adsorbed $\mathrm{C}_{3} \mathrm{H}_{4}$ originated from photo polymerization of $\mathrm{C}_{3} \mathrm{H}_{4}$ in $(\mathrm{Na}, \mathrm{H})$-ETS- 10 . 


\section{Acknowledgments}

This work is supported by projects PTDC/EQU-EQU/100476/2008, PEst-C/CTM/LA0011/2013, ProgramaCiência 2007 and ProgramaInvestigador FCT, financed by FEDER through COMPETE - ProgramaOperacionalFactores de Competitividade and by FCT - Fundação para a Ciência e a Tecnologia (Lisbon). RSP gratefully acknowledges a post-doctoral fellowship from FCT with reference SFRH/BPD/70283/2010.

\section{Electronic Supplementary Material}

The online version of thisarticle (doi:10.1007/...) contains supplementarymaterial, which is available to authorized users. 


\section{References}

[1] R.B. Eldridge, Ind. Eng. Chem. Res., 32 (1993) 2208-2212.

[2] J.A. Moulijn, M. Makkee, A. van Diepen, Chemical process technology John Wiley \& Sons, Ltd.2001.

[3] G.E. Keller, A.E. Marcinkowsky, S.K. Verma, K.D. Williamson, Abstr. Pap. Am. Chem. S., 195 (1988) 82-83.

[4] S.H. Cho, S.S. Han, J.N. Kim, K.T. Chue, V.C. Nettem, B. Kumar, US Ptetent 6468329 , 2002.

[5] H. Ogawa, Y. Ito, M. Nakano, K. Itabashi, US Patent 6103208, 2000.

[6] R.T. Yang, P.L. Cen, Ind. Eng .Chem. Proc. Dd., 25 (1986) 54-59.

[7] D.M. Ruthven, S. Farooq, K.S. Knaebel, Pressure Swing Adsorption, Wiley-VCH, New York, 1994.

[8] J. Padin, S.U. Rege, R.T. Yang, L.S. Cheng, Chem. Eng. Sci., 55 (2000) 4525-4535.

[9] J. Padin, R.T. Yang, Chem. Eng. Sci., 55 (2000) 2607-2616.

[10] J. Padin, R.T. Yang, C.L. Munson, Ind. Eng. Chem. Res., 38 (1999) 3614-3621.

[11] R.T. Yang, E.S. Kikkinides, AIChE, 41 (1995) 509-517.

[12] W. Zhu, F. Kapteijn, J.A. Moulijn, Chem. Commun. , (1999) 2453-2454.

[13] S.M. Kuznicki, US Patent 4853202 (1989).

[14] M.W. Anderson, O. Terasaki, T. Ohsuna, A. Philippou, S.P. Mackay, A. Ferreira, J. Rocha, S. Lidin, Nature, 367 (1994) 347-351.

[15] N.A. Al-Baghli, K.F. Loughlin, J. Chem. Eng. Data, 51 (2006) 248-254.

[16] A. Anson, C.C.H. Lin, T.M. Kuznicki, S.M. Kuznicki, Chem. Eng. Sci., 65 (2010) 807-811.

[17] I. Tiscornia, S. Irusta, P. Pradanos, C. Tellez, J. Coronas, J. Santamaria, J. Phys. Chem. C, 111 (2007) 4702-4709.

[18] N.A. Al-Baghli, K.F. Loughlin, J. Chem. Eng. Data, 50 (2005) 843-848.

[19] A. Anson, C.C.H. Lin, S.M. Kuznicki, J.A. Sawada, Chem. Eng. Sci., 64 (2009) 3683-3687.

[20] A.M. Avila, F. Yang, M. Shi, S.M. Kuznicki, Chem. Eng. Sci., 66 (2011) 2991-2996.

[21] R.S. Pillai, M. Jorge, J.R.B. Gomes, Microporous Mesoporous Mater., 190 (2014) 38-45.

[22] M. Guo, E.A. Pidko, F. Fan, Z. Feng, J.P. Hofmann, B.M. Weckhuysen, E.J.M. Hensen, C. Li, J. Phys. Chem. C, 116 (2012) 17124-17133.

[23] W.Y. Ching, Y.N. Xu, Z.Q. Gu, Phys. Rev. B, 54 (1996) 15585-15589.

[24] A.M. Zimmerman, D.J. Doren, R.F. Lobo, J. Phys. Chem. B, 110 (2006) 8959-8964. 
[25] K. Lee, W.C. Isley, A.L. Dzubak, P. Verma, S.J. Stoneburner, L.-C. Lin, J.D. Howe, E.D. Bloch, D.A. Reed, M.R. Hudson, C.M. Brown, J.R. Long, J.B. Neaton, B. Smit, C.J. Cramer, D.G. Truhlar, L. Gagliardi, J. Am. Chem. Soc., 136 (2013) 698-704.

[26] A. Simperler, R.G. Bell, A. Philippou, M.W. Anderson, J. Phys. Chem. B, 106 (2002) 10944-10954.

[27] D.F. Plant, A. Simperler, R.G. Bell, J. Phys. Chem. B, 110 (2006) 6170-6178.

[28] Y. Zhao, D.G. Truhlar, J. Chem. Phys., 125 (2006) 194101.

[29] M.J. Frisch, G.W. Trucks, H.B. Schlegel, G.E. Scuseria, M.A. Robb, J.R. Cheeseman, G. Scalmani, V. Barone, B. Mennucci, G.A. Petersson, H. Nakatsuji, M. Caricato, X. Li, H.P. Hratchian, A.F. Izmaylov, J. Bloino, G. Zheng, J.L. Sonnenberg, M. Hada, M. Ehara, K. Toyota, R. Fukuda, J. Hasegawa, M. Ishida, T. Nakajima, Y. Honda, O. Kitao, H. Nakai, T. Vreven, J. Montgomery, J. A., J.E. Peralta, F. Ogliaro, M. Bearpark, J.J. Heyd, E. Brothers, K.N. Kudin, V.N. Staroverov, R. Kobayashi, J. Normand, K. Raghavachari, A. Rendell, J.C. Burant, S.S. Iyengar, J. Tomasi, M. Cossi, N. Rega, J.M. Millam, M. Klene, J.E. Knox, J.B. Cross, V. Bakken, C. Adamo, J. Jaramillo, R. Gomperts, R.E. Stratmann, O. Yazyev, A.J. Austin, R. Cammi, C. Pomelli, J.W. Ochterski, R.L. Martin, K. Morokuma, V.G. Zakrzewski, G.A. Voth, P. Salvador, J.J. Dannenberg, S. Dapprich, A.D. Daniels, Ö. Farkas, J.B. Foresman, J.V. Ortiz, J. Cioslowski, D.J. Fox, Gaussian 09, Rev. B.01, Gaussian, Inc., Wallingford CT, (2009).

[30] R. Valero, J.R.B. Gomes, D.G. Truhlar, F. Illas, J. Chem. Phys., 129 (2008) 124710: 124711 $-124717$.

[31] R. Valero, J.R.B. Gomes, D.G. Truhlar, F. Illas, J. Chem. Phys., 132 (2010) 104701: 104701 $-104712$.

[32] J. Toda, M. Fischer, M. Jorge, J.R.B. Gomes, Chem. Phys. Lett., 587 (2013) 7-13.

[33] S.J. Luo, Y. Zhao, D.G. Truhlar, J. Phys. Chem. Lett., 3 (2012) 2975-2979.

[34] L. Ferrighi, G.K.H. Madsen, B. Hammer, J. Chem. Phys., 135 (2011) 084704: 084701 084707.

[35] J.P. Prates Ramalho, J.R.B. Gomes, F. Illas, RSC Adv., 3 (2013) 13085-13100.

[36] I.W. Ashworth, I.H. Hillier, D.J. Nelson, J.M. Percy, M.A. Vincent, What is the initiation step of the Grubbs-Hoveyda olefin metathesis catalyst?, Chem Commun, 47 (2011) 5428-5430.

[37] S. Pandian, I.H. Hillier, M.A. Vincent, N.A. Burton, I.W. Ashworth, D.J. Nelson, J.M. Percy, G. Rinaudo, Prediction of ring formation efficiency via diene ring closing metathesis (RCM) reactions using the M06 density functional, Chem Phys Lett, 476 (2009) 37-40.

[38] Y. Zhao, D.G. Truhlar, Attractive Noncovalent Interactions in the Mechanism of Grubbs Second-Generation Ru Catalysts for Olefin Metathesis, Organic Letters, 9 (2007) 1967-1970.

[39] Y. Zhao, D.G. Truhlar, Benchmark Data for Interactions in Zeolite Model Complexes and Their Use for Assessment and Validation of Electronic Structure Methods, The Journal of Physical Chemistry C, 112 (2008) 6860-6868.

[40] S.M. Kuznicki, A. Anson, A. Koenig, T.M. Kuznicki, T. Haastrup, E.M. Eyring, D. Hunter, J. Phys. Chem. C, 111 (2007) 1560-1562. 
[41] M. Shi, Applications of titanosilicate molecular sieve in gas separation Department of Chemical and Materials Engineering, University of Alberta Edmonton, Alberta 2013, pp. 1-182.

[42] A. Zecchina, C. Otero Arean, G. Turnes Palomino, F. Geobaldo, C. Lamberti, G. Spoto, S. Bordiga, Phys. Chem. Chem. Phys., 1 (1999) 1649-1657.

[43] M. Kishima, T. Okubo, J. Phys. Chem. B, 107 (2003) 8462-8468.

[44] Y.K. Krisnandi, R.F. Howe, Appl. Catal., A, 307 (2006) 62-69.

[45] F.X. Llabrés i Xamena, A. Zecchina, Phys. Chem. Chem. Phys., 4 (2002) 1978-1982.

[46] J.R.B. Gomes, M.A.V.R. Da Silva, Int. J. Quantum Chem., 101 (2005) 860-868.

[47] X.Q. Wang, A.J. Jacobson, Chem. Commun., (1999) 973-974.

[48] S. Simon, M. Duran, J.J. Dannenberg, J. Chem. Phys., 105 (1996) 11024-11031.

[49] R.S. Pillai, J.R.B. Gomes, M. Jorge, Langmuir, (2014).

[50] J.P. Foster, F. Weinhold, J. Am. Chem. Soc., 102 (1980) 7211-7218.

[51] A.E. Reed, R.B. Weinstock, F. Weinhold, J. Chem. Phys., 83 (1985 ) 735 - 746.

[52] A.E. Reed, F. Weinhold, J. Chem. Phys., 83 (1985) 1736 - 1740.

[53] A.E. Reed, L.A. Curtiss, F. Weinhold, Chem. Rev., 88 (1988) 899-926.

[54] T. Lu, F. Chen, J. Comp. Chem. , 33 (2012) 580-592.

[55] S.M. Kuznicki, K.A. Thrush, F.M. Allen, S.M. Levine, M.M. Hamil, D.T. Hayhurst, M. Mansour, Synth. Microporous Mater., Vol 1, (1992) 427-453.

[56] D.M. Ruthven, K.F. Loughlin, , J. Chem. Soc., Faraday Trans. 1, 68 (1972) 696-708.

[57] R.I. Derrah, K.F. Loughlin, D.M. Ruthven, J. Chem. Soc., Faraday Trans. 1, 68 (1972 ) 1947-1955.

[58] R.F.W. Bader, Atoms in Molecules, Oxford University Press, Oxford, 1990.

[59] A.D. Becke, K.E. Edgecombe, J. Chem. Phys., 92 (1990) 5397.

[60] B. Silvi, J. Phys. Chem. A, 107 (2003) 3081.

[61] M.L. Guo, Z.C. Feng, G.N. Li, J.P. Hofmann, E.A. Pidko, P. Magusin, Q. Guo, B.M. Weckhuysen, E.J.M. Hensen, F.T. Fan, C. Li, Chem. - Eur. J., 18 (2012) 12078-12084.

[62] X. Yang, J.L. Paillaud, H.F.W.J. van Breukelen, H. Kessler, E. Duprey, Microporous Mesoporous Mater., 46 (2001) 1-11.

[63] I.M. Alecu, J.J. Zheng, Y. Zhao, D.G. Truhlar, J Chem Theory Comput, 6 (2010) 28722887.

[64] A. Zecchina, F.X.L.I. Xamena, C. Paze, G.T. Palomino, S. Bordiga, C.O. Arean, Phys. Chem. Chem. Phys., 3 (2001) 1228-1231. 